\title{
PENGARUH KUALITAS PELAYANAN DAN HARGA TERHADAP KEPUASAN PELANGGAN
}

\author{
AB. Christono \\ UniSadhuGuna Business School \\ Email: ab.christono@ubs-usg.ac.id
}

\begin{abstract}
Abstrak
Penelitian ini bertujuan untuk mengetahui pengaruh kualitas pelayanan dan harga terhadap kepuasan pelanggan. Penelitian ini juga bertujuan untuk mengetahui keunggulan dan kelemahan dari zigot training yang dirasakan oleh pelanggan sehingga dapat dijadikan bahan pertimbangan dalam menyusun kebijakan dan strategi pemasaran yang tepat. Lokasi penelitian dilakukan di PT zigot mediatama dengan jumlah sampel business to business 65 responden menggunakan metode probability sampling. Jenis penelitian ini adalah deskriptif verifikatif dengan pendekatan kuantitatif dan kualitatif. Metode analisis yang digunakan adalah analisis regresi linear berganda dan menggunakan program SPSS versi 20. Hipotesis dalam penelitian ini menduga bahwa kualitas pelayanan, harga serta kualitas pelayanan dan harga secara bersama-sama (simultan) mempengaruhi kepuasan pelanggan. Hasil penelitian menunjukkan bahwa kualitas pelayanan dan harga berpengaruh secara signifikan terhadap kepuasan pelanggan yang berarti bahwa pelanggan merasa puas dengan kualitas pelayanan dan harga yang diberikan. Hasil temuan dalam penelitian ini diketahui adanya beberapa indikator yang menjadi keunggulan dari perusahaan yang harus dipertahankan dan ada juga beberapa indikator yang masih menjadi kelemahan yang harus diperbaiki. Temuan lain penelitian ini menunjukkan bahwa persentase sumbangan pengaruh variabel independen (kualitas pelayanan dan harga) sebesar 59,4\% terhadap variabel dependen (kepuasan pelanggan) sedangkan sisanya sebesar 40,6\% dipengaruhi oleh variabel lain yang tidak diteliti.
\end{abstract}

Kata kunci: kualitas pelayanan; harga; kepuasan pelanggan; servqual

\section{Pendahuluan}

Pelanggan adalah inti dari perusahaan. Perusahaan dapat hidup dan berkembang karena mempunyai pelanggan-pelanggan yang memberikan keuntungan bagi perusahaan. Meningkatnya kebutuhan akan Sumber Daya Manusia (SDM) yang kompeten dan berkualitas untuk mendukung produktivitas perusahaan, menuntut perusahaan untuk dapat dengan baik mengelola dan mengembangkan keterampilan dan kemampuan pegawainya agar dapat bersaing mengikuti perkembangan lingkungan dunia usaha yang semakin kompetitif. Dengan adanya tuntutan tersebut, banyak perusahaan yang memberikan anggaran tersendiri, khusus untuk pengembangan skill dan keterampilan karyawannya melalui pendidikan dan pelatihan (training). Akibatnya, banyak bermunculan usaha jasa pendidikan dan pelatihan (training) serta konsultasi di Indonesia. 
Sebagai perusahaan penyedia jasa training, PT Zigot Mediatama merasakan ketatnya persaingan di industri ini. Untuk dapat mewujudkan rasa puas tentunya penyedia jasa harus memberikan pelayanan lebih dari apa yang diharapkan oleh peserta. Kepuasan pelanggan merupakan suatu perasaan senang atau kecewa seseorang yang muncul setelah membandingkan antara persepsi atau kesannya terhadap kinerja (hasil) suatu produk yang dihasilkan oleh perusahaan (Philip Kotler, 2005).

Ada banyak faktor yang mempengaruhi kepuasan pelanggan seperti kualitas pelayanan dan harga. Kualitas layanan merupakan suatu bentuk penilaian konsumen terhadap tingkat layanan yang diterima (perceived service) dengan tingkat layanan yang diharapkan (expected service). Sedangkan harga adalah satu-satunya unsur dalam berbagai unsur bauran pemasaran yang akan mendatangkan laba bagi pelaku usaha. Berdasarkan hasil observasi awal peneliti terhadap kepuasan pelanggan dalam hal kualitas pelayanan dan harga, secara umum sudah baik, akan tetapi masih terdapat keluhan-keluhan dari beberapa pelanggan yang merasa belum puas dalam hal pelayanan yang mereka terima dengan harga yang mereka bayarkan. Berdasarkan permasalahan di atas, maka penulis merasa perlu untuk melakukan penelitian terkait dengan kualitas pelayanan dan harga terhadap kepuasan pelanggan.

Hipotesis adalah jawaban sementara terhadap rumusan masalah penelitian (Sugiyono, 2005:54). Hipotesis dalam penelitian ini adalah sebagai berikut:

H1: Kualitas pelayanan berpengaruh terhadap kepuasan pelanggan

H2: Harga berpengaruh terhadap kepuasan pelanggan

H3: Kualitas pelayanan dan harga secara bersama-sama (simultan)

berpengaruh terhadap kepuasan pelanggan Zigot Training

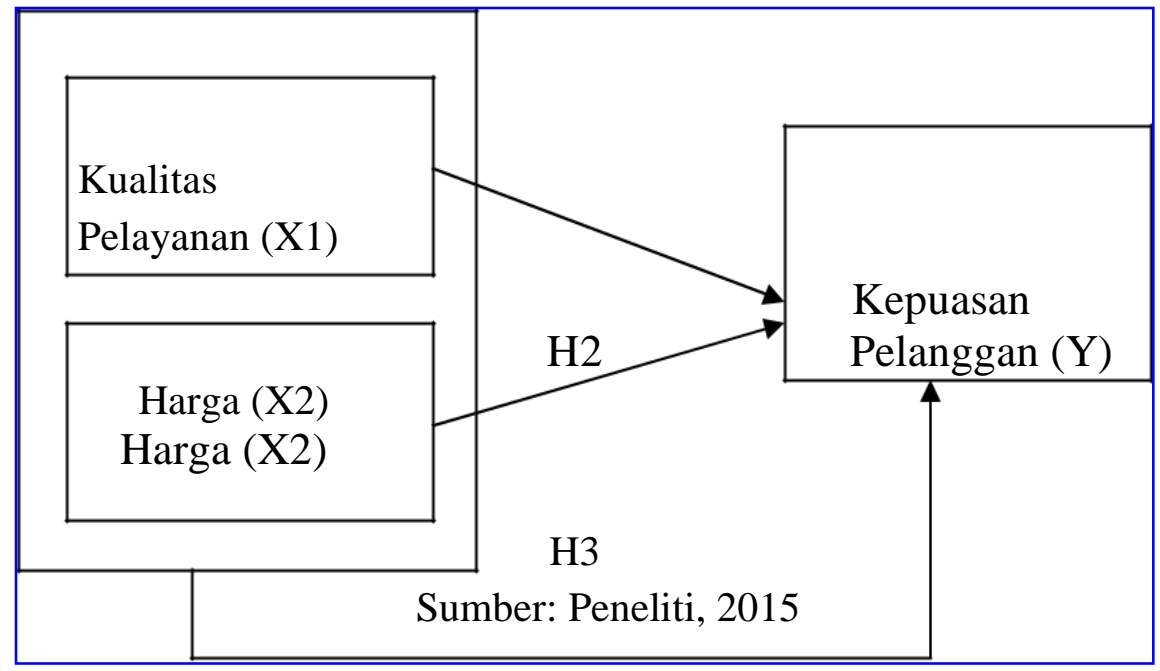

Tujuan dilakukan penelitian ini adalah untuk mengetahui apakah ada pengaruh kualitas pelayanan dan harga secara parsial maupun simultan terhadap kepuasan pelanggan di PT Zigot Mediatama. 


\section{Metode Penelitian}

\section{Jenis Penelitian}

Jenis penelitian ini adalah deskriptif verifikatif dengan pengukuran teknik analisa kuantitatif dan kualitatif dengan model analisis regresi linear berganda (multiple regression). Pengujian data penelitian menggunakan program SPSS versi 20, sedangkan untuk transformasi data penelitian ke dalam bentuk yang mudah dipahami atau diinterpretasikan, penelitian ini menggunakan analisis deskriptif.

2. Lokasi dan Waktu Penelitian

Lokasi penelitian bertempat di PT Zigot Mediatama-Zigot Training Center, Jalan Aria Putra Raya No. 5 (Kavling Keuangan) Ciputat, Tangerang Selatan. Sedangkan waktu penelitian dimulai pada bulan September 2014 - Februari 2015

3. Jenis Data

Sumber data yang digunakan dalam penelitian ini adalah data primer dan sekunder. Pada penelitian ini, data primer diperoleh secara langsung dari sumbernya, diamati dan dicatat untuk pertama kalinya melalui metode penyebaran angket (kuesioner) kepada responden (pelanggan Zigot Training Center). Sedangkan data sekunder diperoleh dari berbagai bahan pustaka, baik berupa buku, jurnal-jurnal dan dokumen-dokumen terkait yang ada hubungannya dengan materi kajian.

4. Populasi dan Sampel

Dalam penelitian ini populasi berjumlah 153 orang dan jumlah sampel sebanyak 65 responden. Teknik pengambilan sampel dalam penelitian ini dilakukan menggunakan probability sampling dengan teknik simple random sampling, yaitu cara pengambilan sampel dari anggota populasi secara acak tanpa memperhatikan strata (tingkatan) yang ada dalam anggota populasi.

5. Skala Pengukuran Variabel

Pengukuran pengaruh kualitas pelayanan dan harga terhadap kepuasan pelanggan melalui skala Likert. Skala likert digunakan untuk mengukur sikap, pendapat dan persepsi seseorang atau kelompok orang tentang fenomena sosial. Jawaban setiap item instrumen yang menggunakan skala likert mempunyai gradasi dari sangat positif sampat sangat negatif, yang dapat berupa kata-kata sangat setuju, setuju, ragu-ragu, tidak setuju dan sangat tidak setuju (Sugiyono, 2000). Dalam penelitian ini pemberian skor pada kuesioner adalah sebagai berikut:

a. Jawaban sangat tidak puas (STP) dan sangat tidak setuju (STS) diberi skor 1

b. Jawaban tidak puas (TP) dan tidak setuju (TS) diberi skor 2

c. Jawaban netral $(\mathrm{N})$ diberi skor 3

d. Jawaban puas (P) dan setuju (S) diberi skor 4

e. Jawaban sangat puas (SP) dan sangat setuju (SS) diberi skor 5.

6. Definisi Operasional Variabel

Definisi operasional dalam penelitian ini variabel-variabel yang diteliti adalah sebagai berikut: 


\section{Tabel 1}

\section{Definisi Operasional Variabel dan Pengukuran Penelitian}

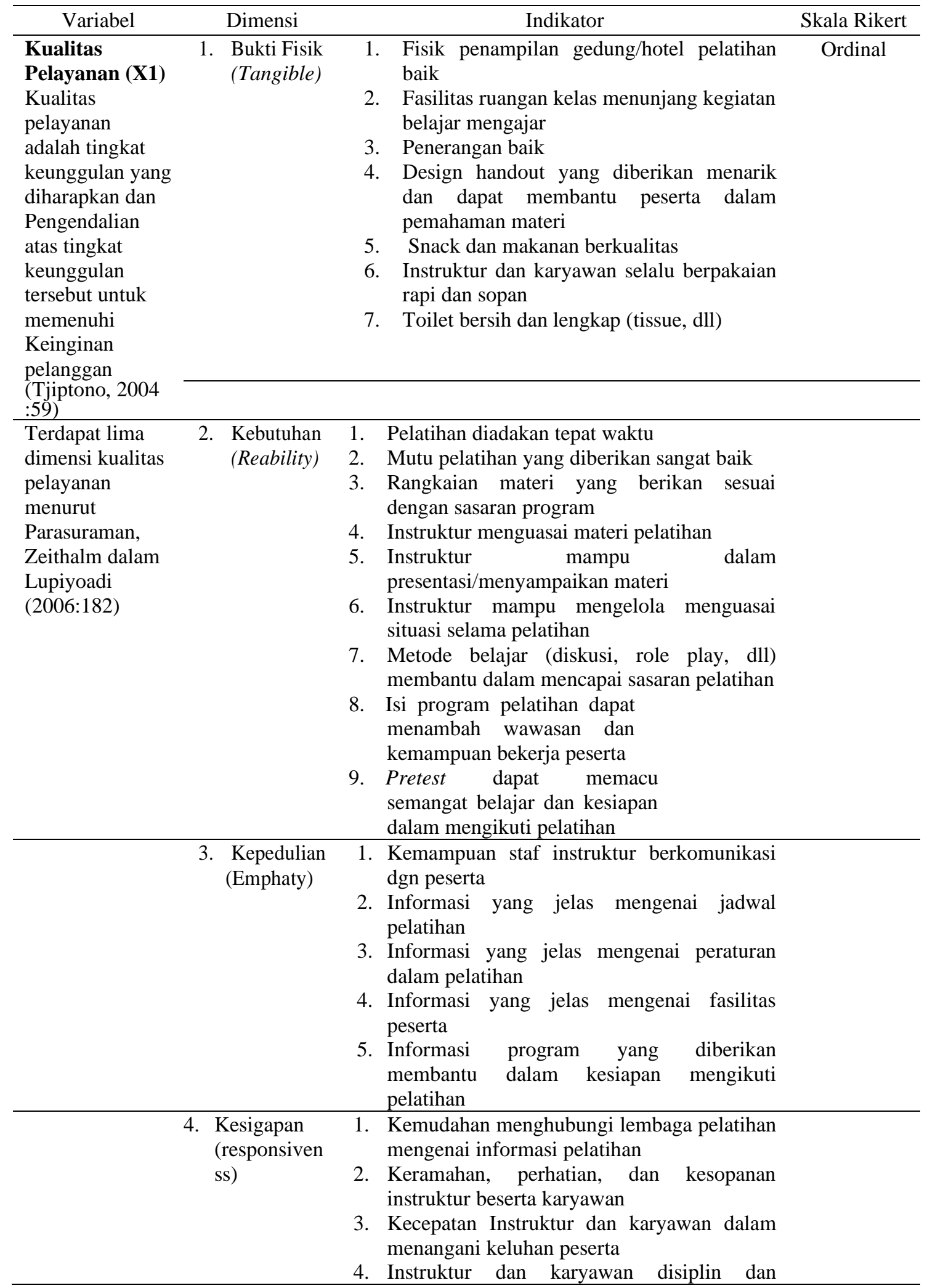




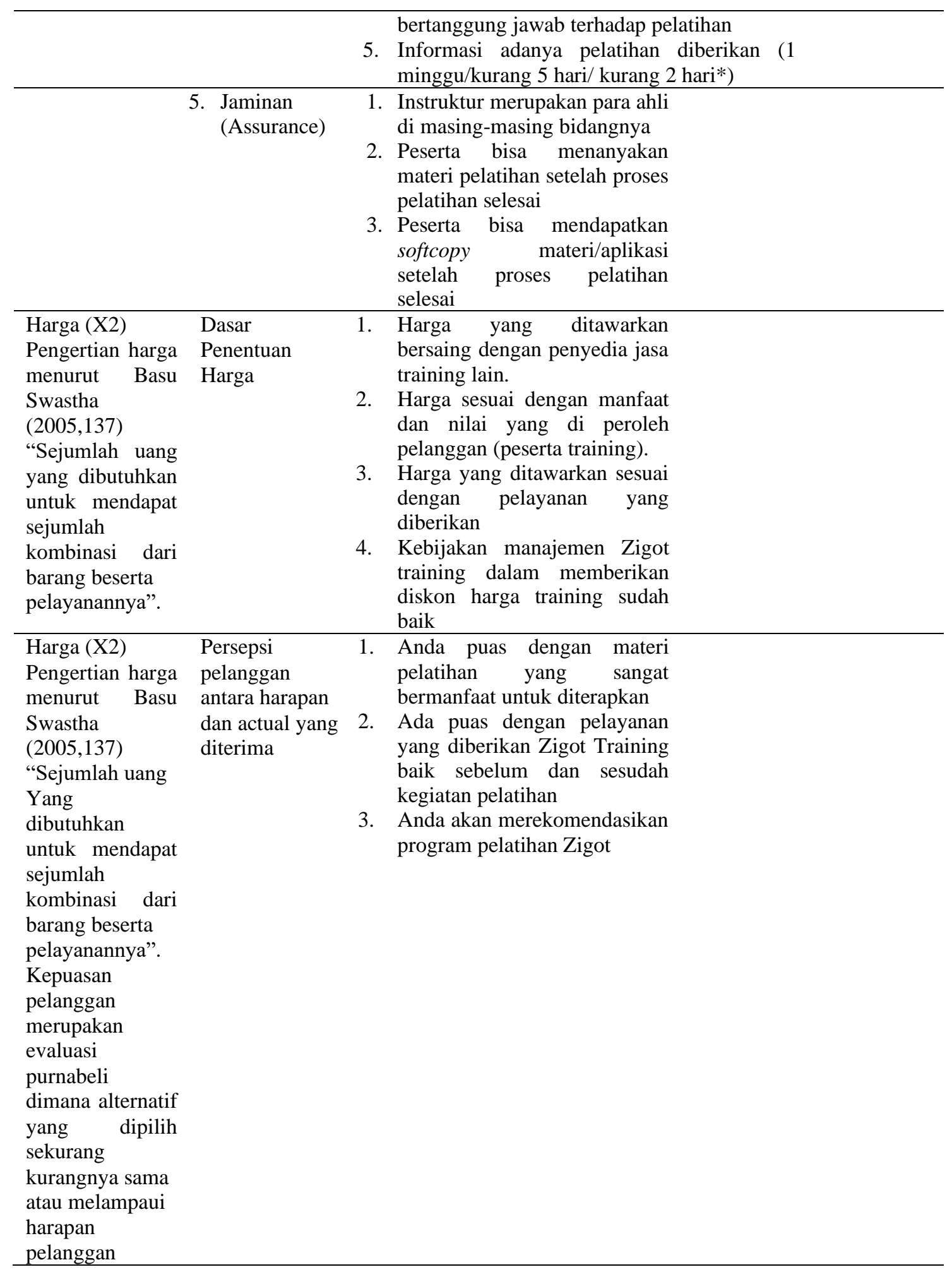

\section{Alat Analisis Data}

\section{a. Uji Instrumen}

\section{Uji Validitas}

Uji validitas digunakan untuk mengukur sah atau valid tidaknya suatu kuesioner. Kuesioner dikatakan valid jika pertanyaan kuesioner mampu 
mengungkapkan sesuatu yang akan diukur oleh kuesioner tersebut (Ghozali, 2012).

\section{Uji Reliabilitas}

Uji Reliabilitas merupakan alat untuk mengukur suatu kuesioner yang merupakan indikator dari variabel atau kosntruk. Suatu kuesioner dikatakan reliabel atau handal jika jawaban seseorang terhadap pertanyaan konsisten atau stabil dari waktu ke waktu. SPSS memberikan fasilitas untuk mengukur reliabilitas dengan uji statistik Cronbach Alpha $(\alpha)$. Suatu variabel dikatakan reliabel jika memberikan nilai $\alpha>0,60$ (Ghozali, 2006).

b. Uji Asumsi Klasik

\section{Uji Normalitas}

Uji normalitas bertujuan untuk mengetahui apakah dalam model regresi, variabel terikat, variabel bebas atau keduanya mempunyai distribusi normal atau tidak, karena suatu model regresi yang baik adalah yang memiliki distribusi residual normal atau mendekati normal. Untuk menguji normalitas dalam penelitian ini, peneliti menggunakan uji statistik Kolmogorov-Smirnov. Data dinyatakan normal jika signifikansi (Asym.Sig) $>0,05$.

2. Uji Multikolinearitas

Uji multikolinearitas adalah suatu pengujian yang bertujuan untuk menguji apakah dalam suatu model regresi ditemukan adanya korelasi atau hubungan antar variabel bebas. Dalam model regresi yang baik seharusnya tidak terjadi korelasi diantara variabel bebas (Ghozali, 2006). Dasar pengambilan keputusan dapat dilakukan dengan melihat apakah nilai tolerance > 0,10 maka tidak terjadi multikolinearitas atau dengan melihat apakah nilai VIF > 10,00 maka tidak terjadi multikolinearitas.

\section{Uji Heteroskedastisitas}

Uji heteroskedastisitas bertujuan untuk menguji apakah dalam model regresi terjadi ketidaksamaan variance dari residual satu pengamatan ke pengamatan yang lain. Jika variance dari residual satu pengamatan ke pengamatan lain tetap, maka disebut homoskedastisitas dan jika berbeda maka disebut heteroskedastisitas. Pada penelitian ini dilakukan uji heteroskedastisitas dengan menggunakan metode glesjer. Dasar pengambilan keputusan pada pengujian heteroskedastisitas dengan uji Glesjer ialah jika nilai Sig > 0,05 maka tidak terjadi Heteroskedastisitas.

c. Analisis Regresi Linear Berganda

Menurut Duwi Prayitno (2010:61) "Analisis regresi linear berganda adalah hubungan secara linear antara dua atau lebih variabel independen (X1, X2...Xn) dengan variabel dependen (Y). Dalam penelitian ini, digunakan model regresi linear berganda. Rumusnya adalah sebagai berikut:

$$
\mathrm{Y}=\alpha+\mathrm{b} 1 \mathrm{X} 1+\mathrm{b} 2 \mathrm{X} 2+\mathrm{e}
$$


Di mana:

$\mathrm{Y}=$ Variabel terikat yaitu kepuasan pelanggan

$\mathrm{A}=$ Konstanta

b1= Koefisien regresi variabel Kualitas Pelayanan (X1)

b2 $=$ Koefisien regresi variabel Harga

$\mathrm{X} 1=$ Variabel bebas yaitu kualitas pelayanan

$\mathrm{X} 2=$ Variabel bebas yaitu harga

$\mathrm{E}=$ Standar Eror

d. Pengujian Hipotesis Penelitian

1. Uji Signifikan Parameter Individual (Uji Statistik t)

Uji t dikenal dengan uji parsial, yaitu untuk menguji bagaimana pengaruh masing-masing variabel bebasnya secara sendiri-sendiri terhadap variabel terikatnya. Dasar pengambilan keputusan pengujian ini adalah dengan membandingkan Nilai thitung dengan nilai ttabel yaitu:

a) Apabila nilai t hitung $>$ t tabel dan tingkat signifikansi $<\alpha(0,05)$, maka $\mathrm{H} 0$ ditolak dan Ha diterima.

b) Apabila $\mathrm{t}$ hitung $<\mathrm{t}$ tabel dan tingkat signifikansi $>\alpha(0,05)$, maka H0 diterima dan Ha ditolak.

2. Uji Signifikansi Simultan (Uji Statistik F)

Uji F dikenal dengan uji serentak atau uji Model/Uji Anova, yaitu uji untuk melihat bagaimanakah pengaruh semua variabel bebasnya secara bersama-sama terhadap variabel terikatnya. Adapun kriteria pengujian uji $\mathrm{F}$ adalah dengan membandingkan nilai $\mathrm{F}$ hitung dan $\mathrm{F}$ tabel sebagai berikut:

a) Apabila $\mathrm{F}$ hitung $>\mathrm{F}$ tabel, maka $\mathrm{H} 1$ diterima.

b) Apabila F hitung < F tabel, maka H1 ditolak.

e. Analisis Korelasi Berganda

Analisis korelasi berganda berfungsi untuk mencari besarnya hubungan dan kontribusi dua variabel bebas $(\mathrm{X})$ atau lebih secara simultan (bersama-sama) dengan variabel terikat (Y). Nilai $\mathrm{R}$ berkisar antara 0 sampai 1, nilai semakin mendekati 1 berarti hubungan yang terjadi semakin kuat, sebaliknya nilai yang semakin mendekati 0, maka hubungan yang terjadi semakin lemah (Sugiyono, 2007).

\section{Hasil dan Pembahasan}

1. Uji Instrumen

a. Uji Validitas

Tabel 2

Hasil Uji Validitas (XI)

\begin{tabular}{cccc}
\hline No Item & rHitung & rTabel 5\%(65) & Kriteria \\
\hline 1 & 0,720 & 0,244 & Valid \\
\hline 2 & 0,678 & 0,244 & Valid \\
\hline 3 & 0,602 & 0,244 & Valid \\
\hline 4 & 0,721 & 0,244 & Valid \\
\hline
\end{tabular}




\begin{tabular}{|c|c|c|c|}
\hline 5 & 0,722 & 0,244 & Valid \\
\hline 6 & 0,497 & 0,244 & Valid \\
\hline 7 & 0,723 & 0,244 & Valid \\
\hline 8 & 0,589 & 0,244 & Valid \\
\hline 9 & 0,758 & 0,244 & Valid \\
\hline 10 & 0,781 & 0,244 & Valid \\
\hline 11 & 0,717 & 0,244 & Valid \\
\hline 12 & 0,627 & 0,244 & Valid \\
\hline 13 & 0,597 & 0,244 & Valid \\
\hline 14 & 0,662 & 0,244 & Valid \\
\hline 15 & 0,832 & 0,244 & Valid \\
\hline 16 & 0,555 & 0,244 & Valid \\
\hline 17 & 0,580 & 0,244 & Valid \\
\hline 18 & 0,579 & 0,244 & Valid \\
\hline 19 & 0,677 & 0,244 & Valid \\
\hline 20 & 0,663 & 0,244 & Valid \\
\hline 21 & 0,648 & 0,244 & Valid \\
\hline 22 & 0,692 & 0,244 & Valid \\
\hline 23 & 0,576 & 0,244 & Valid \\
\hline 24 & 0,678 & 0,244 & Valid \\
\hline 25 & 0,730 & 0,244 & Valid \\
\hline 26 & 0,647 & 0,244 & Valid \\
\hline 27 & 0,619 & 0,244 & Valid \\
\hline 28 & 0,604 & 0,244 & Valid \\
\hline 29 & 0,675 & 0,244 & Valid \\
\hline
\end{tabular}

Sumber: Data primer, diolah, 2015

Tabel 3

\section{Ringkasan Hasil Uji Validitas Harga (X2)}

\begin{tabular}{clcc}
\hline No Item & rHitung & rTabel 5\% (65) & Kriteria \\
\hline $\mathbf{1}$ & 0,908 & 0,244 & Valid \\
\hline $\mathbf{2}$ & 0,927 & 0,244 & Valid \\
\hline $\mathbf{3}$ & 0,881 & 0,244 & Valid \\
\hline $\mathbf{4}$ & 0,870 & 0,244 & Valid \\
\hline
\end{tabular}

Sumber: Data primer, diolah, 2015

Tabel 4

Ringkasan Hasil Uji Validitas Variabel Kepuasan Pelanggan (Y)

\begin{tabular}{cccc}
\hline No Item & rHitung & rTabel 5\% (65) & Kriteria \\
\hline $\mathbf{1}$ & 0,917 & 0,244 & Valid \\
\hline $\mathbf{2}$ & 0,936 & 0,244 & Valid \\
\hline $\mathbf{3}$ & 0,922 & 0,244 & Valid \\
\hline
\end{tabular}

Sumber: Data primer, diolah, 2015

Hasil uji validitas sebagaimana tabel-tabel di atas, menunjukan bahwa semua nilai rhitung lebih besar datai nilai rtabel pada nilai signifikasi 5\%. Oleh karena 
itu, dapat disimpulkan bahwa semua item dalam angket penelitian ini valid sehingga dapat digunakan sebagai instrumen penelitian.

b. Uji Reliabilitas

\section{Tabel 5}

Ringkasan Hasil Uji Reliabilitas

\begin{tabular}{lccl}
\multicolumn{1}{c}{ Variabel } & $\begin{array}{c}\text { Cronbach's } \\
\text { alpha ( } \boldsymbol{\alpha})\end{array}$ & $\begin{array}{c}\text { Standar } \\
\text { Reliabilitas }\end{array}$ & Kriteria \\
\hline Kualitas Pelayanan (X1) & 0,953 & 0,60 & Reliabel \\
\hline Harga (X2) & 0,908 & 0,60 & Reliabel \\
\hline Kepuasan Pelanggan (Y) & 0,914 & 0,60 & Reliabel \\
\hline
\end{tabular}

Sumber: Data primer, diolah, 2015

Berdasarkan Tabel 5, dapat dilihat ringkasan hasil uji reliabilitas diperoleh nilai Cronbach's alpha lebih besar dari 0,60. Oleh karena itu, dapat disimpulkan bahwa seluruh item dalam penelitian ini reliabel atau konsisten, sehingga dapat digunakan sebagai instrumen penelitian.

2. Uji Asumsi Klasik

a. Uji Normalitas

\begin{tabular}{|c|c|c|}
\hline \multicolumn{3}{|c|}{$\begin{array}{c}\text { 3. } \\
\text { Habel } 6 \\
\text { Hajil Uormalitas }\end{array}$} \\
\hline & \multicolumn{2}{|c|}{$\begin{array}{c}\text { Unstandardized } \\
\text { Residual } \\
\end{array}$} \\
\hline $\mathrm{N}$ & \multirow[t]{2}{*}{ Mean } & 65 \\
\hline Normal parameters $a, b$ & & 0000000 \\
\hline & Std. Deviation & 1,22449955 \\
\hline Most Extreme & Absolute & 086 \\
\hline \multirow[t]{2}{*}{ Differencesx } & Positive & 080 \\
\hline & Negative & -086 \\
\hline Kolmogorov - Smirnov Z & & 692 \\
\hline Asymp. Sig. (2 Tailed) & & 725 \\
\hline
\end{tabular}

Sumber: Data primer, diolah, 2015

Dari Output di atas dapat dilihat bahwa nilai signifikansi (Asymp.Sig) dari unstandardized residual untuk seluruh variabel adalah 0,725 yang berarti nilai signifikansi > dari 0,05, maka dapat disimpulkan bahwa data berdistribusi normal. 
b. Uji Multikolinearitas

\section{Tabel 7}

Hasil Uji Multikolinearitas

\begin{tabular}{rllc}
\hline \multicolumn{3}{c}{ Coefficient a } \\
\hline Model & \multicolumn{2}{c}{ Collinearity Statistic } \\
\hline & & Tolerance & VIF \\
\hline & (Constant) & & 1,454 \\
\hline 1. & $\begin{array}{l}\text { Kualitas } \\
\text { Pelayanan }\end{array}$ &, 688 & \\
\hline & Harga &, 688 & 1,454 \\
\hline
\end{tabular}

a. Dependent Variable: Kepuasan Pelanggan

Sumber: Data primer, diolah, 2015

Dari hasil tabel 7, diperoleh nilai tolerance lebih besar dari 0,10 dan nilai Variance Inflation Factor (VIF) lebih kecil dari 10,00, sehingga dapat disimpulkan data tidak terjadi masalah multikolinearitas.

c. Uji Heteroskedastisitas

Tabel 8

Hasil Uji Heteroskedastisitas

\begin{tabular}{|c|c|c|c|c|c|}
\hline \multicolumn{6}{|c|}{ Coefficient a } \\
\hline \multirow[t]{2}{*}{ Model } & $\begin{array}{r}\text { Unsta } \\
\text { Coe } \\
\end{array}$ & $\begin{array}{l}\text { dized } \\
\text { ents }\end{array}$ & $\begin{array}{l}\text { Standardized } \\
\text { Coefficients }\end{array}$ & $\mathrm{T}$ & Sig \\
\hline & B & $\begin{array}{l}\text { Std. } \\
\text { Error }\end{array}$ & Beta & & \\
\hline Constant & 1,109 & ,761 & & 1,458 &, 150 \\
\hline $\begin{array}{l}\text { 1. Kualitas } \\
\text { Pelayan } \\
\text { an }\end{array}$ & ,009 & ,009 & , 161 & 1,080 & ,248 \\
\hline Harga &,- 085 &, 047 &,- 272 & $-1,822$ & 073 \\
\hline
\end{tabular}

Sumber: Data primer, diolah, 2015

Dari tabel 8 di atas dapat dilihat, hasil uji heteroskedastisitas diperoleh nilai signifikansi lebih besar dari 0,05, sehingga dapat disimpulkan data tidak terjadi masalah heteroskedastisitas.

3. Analisis Regresi Linear Berganda

Tabel 9

Hasil Uji Analisis Regresi Linear Berganda

\begin{tabular}{|c|c|c|c|c|c|}
\hline \multicolumn{6}{|c|}{ Coefficient a } \\
\hline \multirow[t]{2}{*}{ Model } & $\begin{array}{r}\text { Unst } \\
\mathrm{Co}\end{array}$ & $\begin{array}{l}\text { rdized } \\
\text { ents }\end{array}$ & $\begin{array}{c}\text { Standardized } \\
\text { Coefficients }\end{array}$ & $\mathrm{T}$ & Sig \\
\hline & B & $\begin{array}{l}\text { Std. } \\
\text { Error }\end{array}$ & Beta & & \\
\hline Constant & $\begin{array}{c}- \\
329\end{array}$ &, 1217 & &,- 271 & ,788 \\
\hline $\begin{array}{l}\text { 2. Kualitas } \\
\text { Pelayan } \\
\text { an }\end{array}$ & ,075 & ,014 & ,522 & 5,348 & ,000 \\
\hline
\end{tabular}




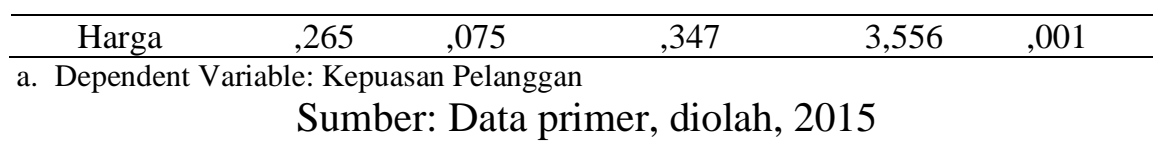

Berdasarkan tabel 9, dapat diperoleh hasil uji regresi linear berganda sebagai berikut:

$$
\begin{aligned}
& Y=\alpha+\beta 1 X 1+\beta 2 X 2+e \\
& Y=-0,329+0,075(X 1)+0,265(X 2)
\end{aligned}
$$

Adapun interpretasi dari persamaan regresi linear berganda tersebut adalah:

a. Konstanta sebesar -0,329 artinya variabel selain kualitas pelayanan dan harga berpengaruh negatif terhadap kepuasan pelanggan dan tidak signifikan.

b. Koefisien regresi variabel kualitas pelayanan (X1) sebesar 0,075, artinya jika diperumpamakan variabel independen lain nilainya tetap dan kualitas pelayanan (X1) mengalami penambahan nilai 1, maka kepuasan pelanggan (Y) akan mengalami peningkatan sebesar 0,075 . Koefisien bernilai positif artinya terjadi hubungan yang positif antara kepuasan pelanggan dengan kualitas pelayanan. Semakin baik kualitas pelayanan yang diberikan, maka kepuasan pelanggan akan semakin meningkat.

c. Koefisien regresi variabel harga (X2) sebesar 0,265, artinya jika diperumpamakan variabel independen lain nilainya tetap dan harga (X2) mengalami penambahan 1, maka kepuasan pelanggan (Y) akan mengalami peningkatan sebesar 0,265. Koefisien bernilai positif artinya terjadi hubungan positif antara kepuasan pelanggan dengan harga, maka jika harga yang ditawarkan semakin menarik, maka akan semakin meningkat pula kepuasan pelanggannya.

4. Pengujian Hipotesis Penelitian

a. Uji Signifikan Parameter Individual (Uji Statistik t)

\section{Tabel 10}

\begin{tabular}{|c|c|c|c|c|c|}
\hline \multicolumn{6}{|c|}{ Coefficient a } \\
\hline \multirow[t]{2}{*}{ Model } & $\begin{array}{r}\text { Unst } \\
\mathrm{Co}\end{array}$ & $\begin{array}{l}\text { rdized } \\
\text { ents }\end{array}$ & $\begin{array}{l}\text { Standardized } \\
\text { Coefficients }\end{array}$ & $\mathrm{T}$ & Sig \\
\hline & B & $\begin{array}{l}\text { Std. } \\
\text { Error }\end{array}$ & Beta & & \\
\hline Constant & $\begin{array}{c}- \\
329\end{array}$ & ,1217 & &,- 271 & ,788 \\
\hline $\begin{array}{l}\text { 3. Kualitas } \\
\text { Pelayan } \\
\text { an } \\
\end{array}$ & ,075 &, 014 & ,522 & 5,348 & ,000 \\
\hline Harga & ,265 &, 075 & ,347 & 3,556 & ,001 \\
\hline
\end{tabular}

\section{Hasil Uji t (Parsial)}

Sumber: Data primer, diolah, 2015

Berdasarkan uji $\mathrm{t}$ (parsial), didapatkan nilai t hitung $>\mathrm{t}$ tabel dari variabel kualitas pelayanan $(5,348>1,999)$ dan harga $(3,556>1,999)$, dan nilai signifikansinya $<0,05$. Sehingga $\mathrm{H} 0$ ditolak dan $\mathrm{H} 1$ dan $\mathrm{H} 2$ diterima yang 
berarti bahwa variabel kualitas pelayanan dan harga secara parsial berpengaruh positif dan signifikan terhadap kepuasan pelanggan (Y).

b. Uji Signifikansi Simultan (Uji Statistik F)

\section{Tabel 11}

Hasil Analisa Uji Simultan (F)

\begin{tabular}{ccccccc}
\multicolumn{7}{c}{ Anova } \\
\hline No & & Sum of squares & Df & Mean & F & Sig. \\
\hline & Regression & 140,654 & 2 & 70,327 & 45,438 &, 000 \\
\hline 1. & Residual & 95,962 & 62 & 1,548 & & \\
\hline Total & 236,651 & 64 & & & \\
\hline
\end{tabular}

Sumber: Data primer, diolah, 2015

Berdasarkan uji $\mathrm{F}$ (simultan), didapatkan nilai $\mathrm{F}$ hitung $>\mathrm{F}$ tabel $(45,438>$ 3,15 ), dan nilai signifikansinya $<0,05$. Sehingga $\mathrm{H} 0$ ditolak dan $\mathrm{H} 3$ diterima yang berarti bahwa variabel kualitas pelayanan dan harga secara simultan berpengaruh positif dan signifikan terhadap kepuasan pelanggan (Y).

c. Analisis Korelasi Berganda

\section{Tabel 12}

Hasil Uji Analisis Korelasi Berganda

\begin{tabular}{|c|c|c|c|c|}
\hline \multicolumn{5}{|c|}{ Model Summary } \\
\hline Model & $\mathrm{R}$ & R Square & Adjusted R Square & $\begin{array}{c}\text { Std. error of the } \\
\text { estimate }\end{array}$ \\
\hline 1 & ,771a & ,594 & ,581 & 1,224 \\
\hline
\end{tabular}

a. Predictors: (Constant), Harga, Kualitas Pelayanan

Sumber: Data primer, diolah, 2015

Berdasarkan tabel 12 Model Summary diketahui bahwa nilai koefisien korelasi (R) sebesar 0,771. hal ini menunjukkan bahwa besarnya hubungan antara kualitas pelayanan dan harga (secara simultan) menunjukkan pengaruh yang kuat terhadap kepuasan pelanggan.

d. Uji Koefisien Determinasi $\left(\mathrm{R}^{2}\right)$

Tabel 13

Hasil Uji Analisis Determinasi

\begin{tabular}{ccccc}
\hline \multicolumn{5}{c}{ Model Summary b } \\
\hline Model & $\mathrm{R}$ & $\mathrm{R}$ Square & Adjusted R Square & Std. error of the estimate \\
\hline 1 &, $771 \mathrm{a}$ &, 594 &, 581 & 1,224 \\
\hline a. Predictors: (Constant), Harga, Kualitas Pelayanan \\
b. Dependent Variable: Kepuasan Pelanggan
\end{tabular}

Sumber: Data primer, diolah, 2015

Berdasarkan analisis data menggunakan alat bantu program SPSS versi 20 diperoleh nilai koefisien determinasi $\mathrm{R}^{2}$ (R Square) sebesar 0,594 atau 59,4\%. Hal ini menjunjkkan bahwa kepuasan pelanggan (Y) dipengaruhi oleh kualitas pelayanan (X1) dan harga (X2) sebesar 59,4\% sedangkan sisanya sebesar $40,6 \%$ dipengaruhi oleh variabel lain yang tidak diteliti. 


\section{Kesimpulan}

Berdasarkan penelitian yang telah dilakukan mengenai "Pengaruh Kualitas Pelayanan dan Harga terhadap Kepuasan Pelanggan” di PT Zigot Mediatama dapat disimpulkan sebagai berikut:

1. Kualitas pelayanan berpengaruh positif dan signifikan terhadap kepuasan pelanggan. Hal ini dapat dibuktikan melalui uji t, dimana hasil uji t memperlihatkan bahwa Thitung> Ttabelyang berarti hipotesis pertama dalam penelitian ini terbukti dan dapat diterima. Dan menunjukkan hasil bahwa responden merasa puas dengan kualitas pelayanan yang diberikan oleh PT Zigot Mediatama.

2. Harga berpengaruh positif dan signifikan terhadap kepuasan pelanggan. Hal ini dapat dibuktikan melalui uji t, dimana hasil uji t memperlihatkan bahwa Thitung> Ttabel yang berarti hipotesis kedua dalam penelitian ini terbukti dan dapt diterima. Dengan demikian, responden merasa puas dengan harga training yang ditawarkan oleh PT Zigot Mediatama.

3. Kualitas pelayanan dan harga secara simultan berpengaruh positif dan signifikan terhadap kepuasan pelanggan. Yang ditunjukkan dengan hasil uji F bahwa Fhitung> Ftabel. Dengan kontribusi pengaruh dari variabel kualitas pelayanan dan harga terhadap kepuasan pelanggan sebesar 59,4\% dan sisanya sebesar 40,6\% dipengaruhi oleh variabel lain yang tidak diteliti.

\section{Saran}

Berdasarkan kesimpulan yang diambil, maka penulis memberikan saran beberapa hal ini:

1. Saran Praktis

\begin{tabular}{|c|c|c|}
\hline No & Keunggulan yang harus dipertahankan & $\begin{array}{c}\text { Kelemahan yang perlu } \\
\text { ditingkatan }\end{array}$ \\
\hline 1. & $\begin{array}{l}\text { Instruktur harus menguasai materi pelatihan, yaitu harus } \\
\text { instruktu harus ahli dan berpengalaman dibidangnya, baik } \\
\text { secara teori maupun praktek (jika materi teknik) }\end{array}$ & $\begin{array}{l}\text { Informasi yang jelas } \\
\text { mengenai peraturan dalam } \\
\text { pelatihan masih kurang } \\
\text { optimal, misalnya adanya } \\
\text { pemberitahuan (briefing) } \\
\text { sebelum memulai pelatihan } \\
\text { kepada peserta mengenai } \\
\text { peraturan tata tertib selama } \\
\text { pelatihan berlangsung } \\
\text { seperti kapan waktu mulai, } \\
\text { waktu break dan waktu } \\
\text { selesai pelatihan, peraturan } \\
\text { tidak diperkenankan } \\
\text { merokok di dalam ruang } \\
\text { pelatihan, handphone harus } \\
\text { di silent agar tidak } \\
\text { mengganggu belajar peserta } \\
\text { lain, peserta diwajibkan } \\
\text { membawa laptop atau tidak } \\
\text { dll. }\end{array}$ \\
\hline
\end{tabular}




\begin{tabular}{|c|c|c|}
\hline & $\begin{array}{l}\text { Instruktur mampu dalam presentasi atau menyampaikan } \\
\text { materi }\end{array}$ & $\begin{array}{l}\text { Informasi yang jelas mengenai } \\
\text { jadwal pelatihan harus tepat } \\
\text { waktu dan konsisten }\end{array}$ \\
\hline 5 & $\begin{array}{l}\text { Keramahan, perhatian, dan } \\
\text { kesopanan instruktur beserta karyawan }\end{array}$ & $\begin{array}{l}\text { Pre test harus dilakukan lebih } \\
\text { terkontrol. }\end{array}$ \\
\hline 6 & $\begin{array}{l}\text { Peserta bisa menanyakan materi pelatihan setelah proses } \\
\text { pelatihan selesai }\end{array}$ & $\begin{array}{l}\text { Informasi yang jelas mengenai } \\
\text { fasilitas yang didapatkan peserta } \\
\text { harus lebihkonsisten, tidak } \\
\text { berubah-ubah atau jika terjadi } \\
\text { perubahan diinfokan ke peserta } \\
\text { terlebih dahulu. }\end{array}$ \\
\hline 7 & $\begin{array}{l}\text { Peserta bisa mendapatkan softcopy materi/aplikasi } \\
\text { setelah proses pelatihan selesai. }\end{array}$ & \\
\hline
\end{tabular}

Mengetahui keunggulan ini, Zigot Training dapat mempertahankannya dan perlu meningkatkan kualitas pelayanan padaindikator-indikator lainnya yang belum menjadi unggulan di Zigot Training pada setiap event training baik sebelum maupun setelah pelaksaan kegiatan pelatihan. Dengan demikian, diharapkan kepuasan pelanggan akan dapat tercipta dengan semakin baik dan dapat meningkatkan jumlah pelanggan dan profit perusahaan tentunya.

2. Saran Akademis

Perlu adanya penelitian lebih lanjut untuk mencari jawaban yang lebih mendalam mengenai pengaruh kualitas pelayanan dan harga terhadap kepuasan pelanggan. Sehingga diharapkan pula dapat mengetahui adanya kemungkinankemungkinan ditemukannya variabel baru yang dapat mempengaruhi kepuasan pelanggan PT Zigot Mediatama. 


\section{DAFTAR PUSTAKA}

American Marketing Association. (2004). Perilaku Konsumen dan Implikasi dalam Strategi Pemasaran. Terjemahan Nugroho Setiadi J. PT. Prenada Media. Jakarta

Anderson, E.W; Fornell, C and Lehmann, D.R, (1994). "Customer Satisfaction, Market Share and Profitability: Findings from Sweden". Journal of Marketing. Vol.58. p.53-66

Baskoro, Eko Mikael. (2011). “Analisis Kepuasan Peserta Terhadap Kualitas”. PT.MEB

Pelatihan Divisi Product Quality Engineering PT. MEB menggunakan Metode SERVQUAL". Skripsi. Program Sarjana Fakultas Teknik, Departemen Teknik Industri UI: Depok.

Basrah, Hendryadi. Konstanta Negatif bagaimana dalam Teori Online. Diambil 23 Maret 2015 dari https://teorionline.wordpress.com/2014/06/24/konstantaintercept-negatif-bagaimana/

Basu Swasta dan T. Hani Handoko, William J. Stanton. (2005). Management Pemasaran Modern. PT. Grasindo Persada: Jakarta.

Berry, L.L. (1983). Relationship Marketing: Emerging Perspective on Service Marketing. Chicago: American Marketing Association.

Buchari Alma. (2007). Manajemen Pemasaran \& Pemasaran Jasa. Bandung: CV. Alfabeta.

Cronin, J. Joseph Jr dan Steven Taylor. (1992). Measuring Service Quality: Reexamination and Extension, Journal of Marketing

Drucker, Peter F. (1973). Management: Task, Responbilities, and Practices. New York: Harpes and Row

Engel, J.F.; et al, (1990). Consumer Behavior, 6th ed. Chicago: The Dryden.

Enis, BM, and KK Cox. (1988). Marketing Classics: A Selection of Influential Articles, 6th ed., Allyn \& Bacon Inc, Massachusetts.

Fardiani, Aprilia Nia. (2013) "Analisis Pengaruh Kualitas Pelayanan, Harga, dan Promosi Terhadap Kepuasan Pelanggan Dryana Bakery \& Cafe". Skripsi. Tidak dipublikasikan. Semarang: Universitas Diponegoro, Semarang.

Fernanda, Adhinda Putri. (2013). "Pengaruh Kualitas Produk, Kualitas Pelayanan, Harga dan Inovasi Terhadap Kepuasan Konsumen”. Skripsi, Tidak

dipublikasikan. Salatiga: Universitas Kristen Satya Wacana. 
Ghozali, Imam. (2006). Statistik Nonpara metrik. Semarang: Badan Penerbit UNDIP

Ghozali, Imam. (2005). Aplikasi Analisis Multivariate dengan Program SPSS. Badan Penerbit Universitas Diponegoro: Semarang.

Haryanto, Ryan Nur. (2010). "Analisis Pengaruh Harga, Produk, Kebersihan, dan Kualitas Pelayanan Terhadap Kepuasan Pelanggan". Skripsi. Tidak dipublikasikan. Semarang: Universitas Diponegoro Semarang.

Hidayat, Anwar. (2012). Uji F dan Uji T. Dalam Uji Statistik diambil 13 Januari 2015 dari http://www.statistikian.com/2013/01/uji-f-dan-uji-t.html

Kartajaya, Hermawan. (2004). Hermawan Kertajaya on Marketing, Jakarta: Gramedia Pustaka Utama.

Kotler Philip, dan Gary Amstrong. (2012). Principles of Marketing, Global Edition, 14 Edition, Pearson Education.

Kotler, Philip. (1997). Manajemen Pemasaran (Marketing Management). Jakarta: PT Prenhallindo.

Kotler, Philip. (2005). Manajamen Pemasaran, Jilid 1 dan 2. Jakarta: PT. Indeks Kelompok Gramedia.

Lubis, Arlina Nurbaity dan Martin. "Pengaruh Harga (Price) dan Kualitas Pelayanan (Service Quality) Terhadap Kepuasan Pasien Rawat Inap”, Jurnal, Medan, 2009

Lupiyoadi, Rambat. (2001). Manajemen Pemasaran Jasa. Jakarta: Salemba Empat.

Natalia Telan, Ariane Catherina. (2011). "Analisis Pengaruh Faktor Teknologi, Kualitas Layanan, dan Fokus Pelanggan Terhadap Kepuasan Pelanggan”. Skripsi. Tidak dipublikasikan. Semarang: Universitas Diponegoro Semarang.

Parasuraman, A.; Valarie A. Zeithaml, and Leonard L. Berry. (1990). Delivering Quality Service, Balancing Customer Perceptions and Expectation. The Free Press, New York.

Parasuraman, A.; Valarie A. Zeithaml, and Leonard L. Berry. (1994). A Conceptual Model of Service Quality and Its Implications for Future Research, Journal of Marketing.

Payne, Adrian, (1993). The Essence of Services Marketing. New Jersey: Prentice Hall.

Peterson, R.A. and Wilson, W.R., (1992), "Measuring Customer Satisfaction: Fact and Artifact", Journal of the Academy of Marketing Science, Vol. 13, No.1, pp.61-71.

Priyatno, Dwi. (2010). Paham Analisa Statistik Data dengan SPSS. Yogyakarta: Media Kom. 
Putra, Yoan Santosa. Eris Dianawati \& Endi Sarwoko. (2013). "Pengaruh Kualitas Pelayanan Terhadap Kepuasan Pelanggan Pengguna Jasa Parkir (studi kasus pada Mahasiswa Universitas Kanjuruhan Malang)". Skripsi. Tidak dipublikasikan. Malang: Universitas Kanjuruhan. Malang.

Roscoe, J.T. (1975). Fundamental Research Statistic for The Behavior Sciencess, Second Edition. New York: Holt, Rinehart and Winston.

Sarjono, Haryadi dan Julianita, Winda. (2011). SPSS vs LISREL. Jakarta: Salemba 4.

Schnaars, Steven P. (1991). Marketing Strategy: A customer Driven Approach.2nd ed. New York: The Free Press.

Schermerhorn, J., J. Hunt, \& R. Osborn. (1991). Managing Organizational Behavior. 4th. Ed. John Wiley \& Sons.

Simamora, Bilson. (2003). Membongkar Kotak Hitam Konsumen. Jakarta: PT. Gramedia Pustaka.

Sriwidodo, Untung dan Ernawati. "Dimensi Kualitas dan Harga Sebagai Faktor Penentu Kepuasan dan Loyalitas Konsumen". Jurnal Ekonomi dan Kewirausahaan Vol.12 No.2, Oktober 2012:166-176

Sugiyono. (2012). Memahami Penelitian Kualitatif. Bandung: Alfabeta

Sugiyono. (2010). Statistika untuk Penelitian. Bandung: Alfabeta.

Sugiyono. (2004). Metode Penelitian Bisnis. Bandung: Alfabeta.

Sutrisni. (2010). “Analisis Pengaruh Kualitas Produk, Kualitas Pelayanan, Desain Produk, Harga dan Kepercayaan Terhadap Loyalitas Pelanggan Indosat IM3". Skripsi. Tidak dipublikasikan. Semarang: Universitas Diponegoro.

Tjiptono, Fandy. (2010). Strategi Pemasaran. Yogyakarta: Andi

Tjiptono, Fandi. (2004). Pemasaran Jasa. Malang: Bayumedia.

Umar. (2003). Pengukuran Tingkat Kepuasan Pelanggan. Jakarta: Gramedia

Valarie A. Zeithaml \& Mary Jo Bitner. 2008., Service Marketing. The McGraw Hill Companies, Inc.

Wilson, Aubrey. (1982). Manajemen Pemasaran Jasa. Jakarta: Pustaka Binuman

Wimono, Yusuf. (2005). “Analisis Pengaruh Kualitas Pelayanan Terhadap Kepuasan Pelanggan Pada PT. Alfa Retailindo Tbk". Tesis. Tidak dipublikasikan. Surakarta: Universitas Muhammadiyah Surakarta. 